Ambiente \& Água - An Interdisciplinary Journal of Applied Science
ISSN 1980-993X - doi:10.4136/1980-993X
www.ambi-agua.net
E-mail: ambi.agua@gmail.com

\title{
Estrutura da vegetação herbácea em paisagens ciliares no sul de Santa Catarina, Brasil
}

\author{
doi:10.4136/ambi-agua.1881
}

Received: 07 Mar. 2016; Accepted: 25 Apr. 2016

\author{
Aline Votri Guislon*; Karoline Ceron; Guilherme Alves Elias; \\ Robson Santos; Vanilde Citadini-Zanette \\ Universidade do Extremo Sul Catarinense (UNESC), Criciúma, SC, Brasil \\ Herbário Pe. Dr. Raulino Reitz (CRI) \\ *Autor correspondente: e-mail: vg_aline@ hotmail.com, \\ karolceron@hotmail.com,guilherme@unesc.net, \\ rsa@unesc.net,vcz@unesc.net
}

\section{RESUMO}

As características estruturais e ecológicas da vegetação herbácea fazem com que ela seja sensível às alterações do ambiente, atuando como indicador da qualidade ambiental. No entanto, o estudo dessa comunidade ainda é incipiente em regiões neotropicais. Este estudo descreve a florística e os aspectos fitossociológicos da vegetação herbácea terrícola na mata ciliar de sete rios, no município de Urussanga, sul do estado de Santa Catarina, além de analisar e quantificar o status do conhecimento científico relacionado às herbáceas terrícolas no Brasil. Foram levantadas 320 unidades amostrais de $4 \mathrm{~m}^{2}$, nas quais todos os indivíduos foram identificados e dados relacionados aos parâmetros fitossociológicos foram coletados. A amostragem resultou em 58 táxons, 38 pertencentes às angiospermas e 20 às samambaias, distribuídos em 25 famílias botânicas. Poaceae apresentou maior riqueza, com 11 espécies. Estruturalmente, destacaram-se Goeppertia monophylla (Vell.) Borchs. e S. Suárez, Blechnum brasiliense Desv. e Heliconia farinosa Raddi. A forma de vida mais frequente foi a hemicriptófita reptante. Os resultados revelam uma elevada riqueza de herbáceas terrícolas adaptadas às condições climáticas das matas ciliares, contribuindo para a diversidade da flora regional. Quanto à produção científica, foram encontrados 50 trabalhos indexados nas bases de dados eletrônicas (1990 a 2015), com destaque ao ano de 2011, que teve maior produção científica enfocando as herbáceas terrícolas. Embora com baixo número, a quantidade de indexações tende a crescer, em virtude do avanço da tecnologia de acesso às bases de dados e pela crescente adesão de periódicos em portais de busca.

Palavras-chave: bibliometria, biodiversidade, fitossociologia, florística, Mata Atlântica.

\section{Structure of herbaceous vegetation in riparian landscapes in Southern Santa Catarina, Brazil}

\begin{abstract}
The structural and ecological characteristics of herbaceous vegetation make it sensitive to environmental changes, acting as environmental quality indicator. However, studies of the herbaceous community are as yet rare in neotropical regions. This paper describes the
\end{abstract}


floristics and phytosociology of terrestrial herbaceous vegetation in the riparian forest of seven rivers near the town of Urussanga, Southern Santa Catarina, Brazil, and also analyzes and quantifies the status of scientific knowledge related to terrestrial herbaceous vegetation in Brazil. The study selected 320 sampling units of $4 \mathrm{~m}^{2}$; species were identified and related data regarding phytosociological parameters were collected. The sampling discovered $58 \operatorname{taxa}$, of which 38 belonged to angiosperms and 20 to ferns, distributed in 25 botanical families. Poaceae was the most prevalent with 11 species. Structurally, Goeppertia monophylla (Vell) Borchs and S. Suárez, Blechnum brasiliense Desv and Heliconia farinosa Raddi stood out. The most common form of life was reptant hemicryptophyte. The results indicate a richness of terrestrial herbaceous vegetation adapted to the climatic conditions of a riparian forest, contributing to diversity of the regional flora. Regarding scientific production, 50 papers were found in electronic databases (1990-2015), with 2011 as the year with greatest scientific production regarding terrestrial herbaceous vegetation. Nevertheless, despite the low number of indexed papers found regarding terrestrial herbaceous vegetation, the amount tends to increase due to advancements in database access technology.

Keywords: Atlantic Rainforest, bibliometrics, biodiversity, floristic, phytosociology.

\section{INTRODUÇÃO}

A importância de florestas ao longo de cursos hídricos, de reservatórios e de lagos fundamenta-se na amplitude de benefícios que este tipo de vegetação traz ao ecossistema (Durigan e Silveira, 1999). Neste contexto, as matas ciliares desempenham funções importantes de conexão entre fragmentos, bem como de preservação das funções ecológicas e hidrológicas do ambiente, adicionadas à qualidade da sua vegetação que está fortemente relacionada à composição do uso da terra no entorno (Fernández et al., 2014).

As florestas nativas, representadas por diferentes biomas, são ecossistemas que há séculos são explorados de forma depredatória (Ferreira e Dias, 2004). A fragmentação florestal tem sido considerada uma das principais ameaças à Floresta Atlântica e à sua biodiversidade, podendo ser causada por diversos fatores, tais como o uso do solo pela agricultura e a abertura de estradas (Freitas et al., 2010; Myers et al., 2000). Devido a sua importância ecológica e constante devastação, muitos estudos foram desenvolvidos no âmbito da Floresta Atlântica (Negrelle, 2006). Nesta floresta, a região fitoecológica da Floresta Ombrófila Densa, que cobria originalmente $31 \%$ do estado de Santa Catarina, Brasil, apresenta a maior diversidade do Estado em decorrência de suas variações altitudinais (Klein, 1978; IBGE, 2012). Atualmente, encontra-se altamente fragmentada, sendo que a maioria de seus remanescentes é constituída por espécies secundárias e pioneiras (Schorn et al., 2012; Vibrans et al., 2013).

No sul de Santa Catarina, Brasil, a Floresta Ombrófila Densa é mais intensamente ocupada por atividades agrícolas e pecuárias, além da presença de cidades e pela extração de carvão mineral, contribuindo para sua fragmentação e isolamento (Sevegnani et al., 2013). Como consequência da lavra de carvão, tanto a céu aberto quanto subterrânea, extensas áreas foram degradadas e tiveram seus recursos naturais comprometidos. Durante muitos anos, foram depositados rejeitos de carvão em banhados e margens de rios, poluindo as águas, contaminando o solo e invadindo terras utilizadas por agricultores (Menezes e Waterkemper, 2009), descaracterizando a vegetação florestal em seu entorno.

No Brasil, o componente herbáceo ainda é pouco conhecido, considerando a grande diversidade de sua flora e a complexidade ambiental das florestas em que se desenvolvem (Santos-Junior, 2014). Além disso, as espécies herbáceas terrícolas têm maior taxa de extinção natural do que plantas de outros estratos, e o acelerado processo de urbanização 
sobre os remanescentes naturais resultam diretamente na perda do patrimônio natural (Fuhro et al., 2005; Gilliam, 2007). A vegetação herbácea, por ser de pequeno porte e com raízes superficiais, torna-se sensíveis às alterações ambientais, atuando como agentes indicadores desse meio (Cestaro et al., 1986; Citadini-Zanette e Baptista, 1989).

Estudos com o estrato lenhoso são mais comuns e detalhados se comparados aos do estrato herbáceo. Contudo, alguns autores no sul do Brasil já abordaram as plantas herbáceas em suas pesquisas, como Citadini-Zanette (1984), Cestaro et al. (1986), Dorneles e Negrelle (1999), Jurinitz e Baptista (2007), Inácio e Jarenkow (2008), Palma et al. (2008), Kozera et al. (2009), Citadini-Zanette et al. (2011), Santos-Junior (2014) e Custódio (2015) em interior de florestas; Müller e Waechter (2001) e Klein et al. (2007) em restinga; e Citadini-Zanette et al. (2014) e Mallmann et al. (2016) em mata ciliar.

Assim posto, este estudo objetivou realizar levantamento florístico e fitossociológico da vegetação herbácea terrícola em remanescentes florestais ao longo dos principais rios do município de Urussanga, sul de Santa Catarina, Brasil. Adicionalmente, por meio de ferramentas bibliométricas, analisou-se a produção científica relacionada a este grupo de plantas, com intuito de verificar o estado da arte dessa temática no meio científico.

\section{MATERIAL E MÉTODO}

A amostragem foi realizada no período de novembro de 2012 a maio de 2014, ao longo de trechos de mata ciliar pertencentes a sete rios que compõem a Sub-bacia do Rio Urussanga, no município de Urussanga, Santa Catarina, Brasil, entre as coordenadas $28^{\circ} 48^{\prime} 72^{\prime \prime}$ e $28^{\circ} 26^{\prime} 19^{\prime \prime}$ S e $49^{\circ} 02^{\prime} 67^{\prime \prime}$ e $49^{\circ} 24^{\prime} 94^{\prime \prime}$ W. O clima da região é classificado, segundo Köppen, como Cfa, mesotérmico úmido, com chuvas normalmente bem distribuídas, e verão quente, onde a temperatura da média normal varia de 17,0 a $19,3^{\circ} \mathrm{C}$, a da média normal das máximas varia de 23,4 a $25,9^{\circ} \mathrm{C}$, e das mínimas de 12,0 a $15,1^{\circ} \mathrm{C}$, enquanto que a precipitação pluviométrica anual varia de 1220 a $1660 \mathrm{~mm}$, com o total anual de dias de chuva entre 102 e 150 (EPAGRI, 2001). No município, predominam Argissolos e Cambissolos (EMBRAPA, 1992) e a vegetação da área de estudo, segundo a classificação do IBGE (2012), é Floresta Ombrófila Densa Submontana e a altitude das áreas amostradas encontrara-se entre 100 e $200 \mathrm{~m}$.

Poaceae, Orchidaceae e Pteridaceae apresentaram o maior número de espécies, 11 , seis e cinco, respectivamente (Figura 1). Este resultado vem ao encontro de outros estudos com vegetação herbácea terrícola na Floresta Atlântica, onde estas três famílias também foram as mais representativas (Citadini-Zanette, 1984; Inácio e Jarenkow, 2008; Palma et al., 2008).

Para caracterização e levantamento da estrutura da vegetação herbácea terrícola, utilizou-se o método de parcelas proposto por Mueller-Dombois e Ellenberg (2002). Foram demarcadas 320 parcelas de $2 \mathrm{~m} \mathrm{x} 2 \mathrm{~m}$, totalizando $1280 \mathrm{~m}^{2}$ de área amostral, estabelecidas em locais mais conservados da floresta, a fim de se obter representatividade florística característica da formação vegetal estudada. Em cada parcela, foram anotadas a presença das espécies herbáceas terrícolas e sua cobertura na parcela, sendo estimada de acordo com a escala de Causton (1988), que avalia, em cinco classes de cobertura, o percentual que a parte aérea da planta ocupa na superfície da parcela. As espécies encontradas também foram classificadas em suas respectivas formas de vida, segundo o sistema de Raunkier (1967, modificado por Mueller-Dombois e Ellenberg, 2002), que leva em consideração, principalmente, a posição das gemas de rebrote na planta. As espécies coletadas férteis foram incorporadas ao Herbário Pe. Dr. Raulino Reitz (CRI), da Universidade do Extremo Sul Catarinense (UNESC). 


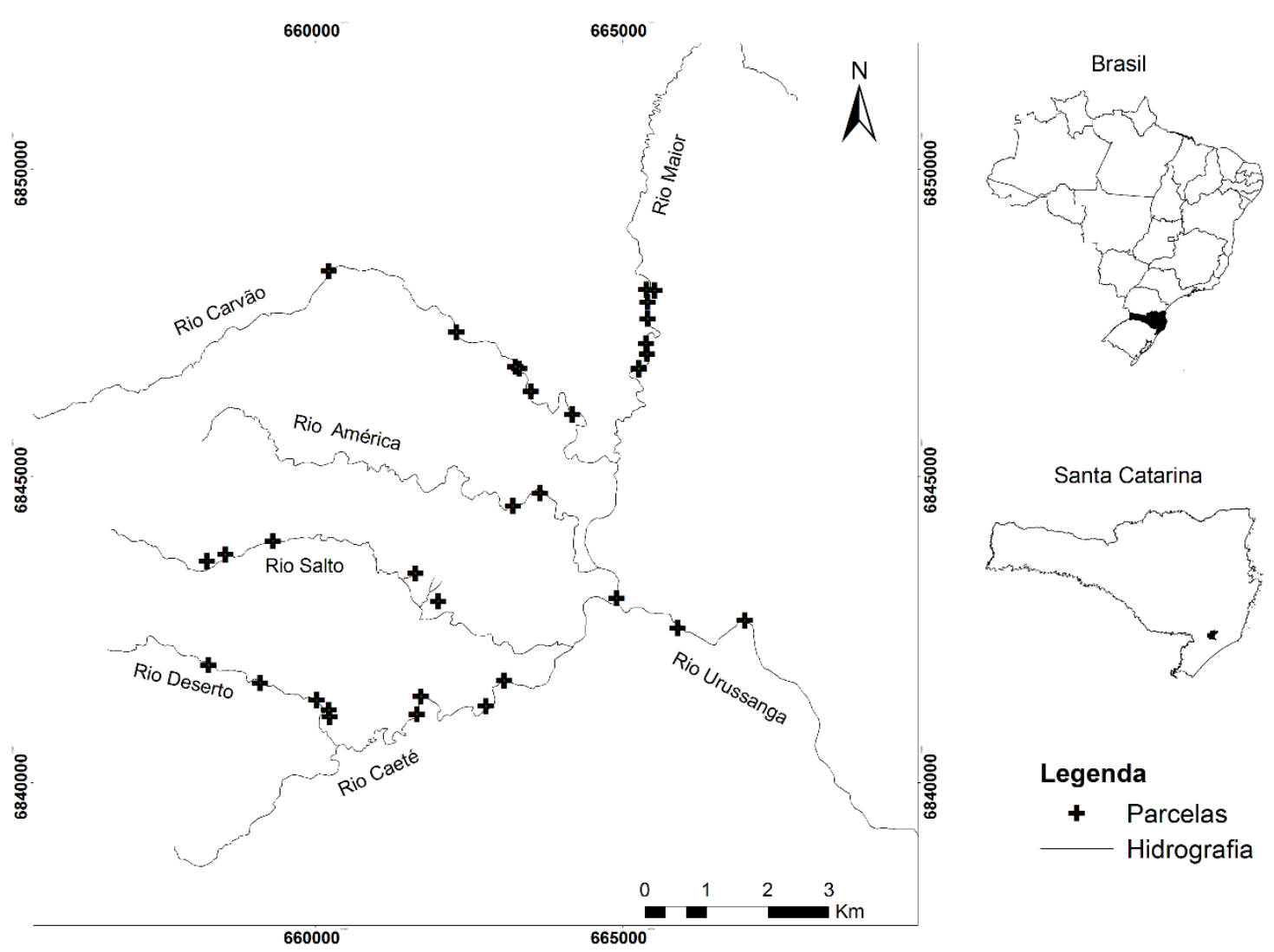

Figura 1. Localização da área de estudo e das unidades amostrais (parcelas) para o levantamento florístico e estrutural da vegetação herbácea terrícola ciliar do município de Urussanga, Santa Catarina, Brasil.

Para analisar a produção científica sobre espécies herbáceas terrícolas florestais, foi realizada análise bibliométrica a partir de duas bases de dados eletrônicas, "SciVerse Scopus" e "Web of Science", com intuito de abranger o maior número de trabalhos. Os termos de busca utilizados foram a combinação "terrestrial herbaceous", pesquisados somente nas partes principais de busca: título, resumo e palavras-chave. A coleta de dados foi feita em janeiro de 2016, limitando o período de buscas até o ano de 2015.

\section{RESULTADOS E DISCUSSÃO}

O levantamento resultou em 58 táxons. Destes, 51 foram identificados em nível específico e sete em nível genérico. Do total, 38 pertencem às angiospermas e 20 às samambaias, distribuídos em 25 famílias botânicas (Figura 2). Dentre as 51 espécies identificadas (Tabela 1), três são exóticas, porém consideradas naturalizadas pela Lista de Espécies da Flora do Brasil (Jardim Botânico, 2016).

A riqueza específica pode ser considerada alta $(n=55)$ ao serem analisados outros estudos fitossociológicos realizados no sul do país, como Citadini-Zanette (1984), Inácio e Jarenkow (2008) e Citadini-Zanette et al. (2011) que amostraram, respectivamente, 17, 29 e 31 espécies herbáceas terrícolas. Ressalta-se, no entanto, que o presente estudo foi realizado em floresta ombrófila, que segundo Hora e Soares (2002), tende a apresentar maior riqueza de espécies de sub-bosque do que as florestas estacionais e, Polisel (2011) destaca que, em um mesmo tipo florestal, a riqueza de plantas herbáceas é muito variável e as fitofisionomias do entorno também podem influenciar a composição de espécies (Polisel et al., 2015). 


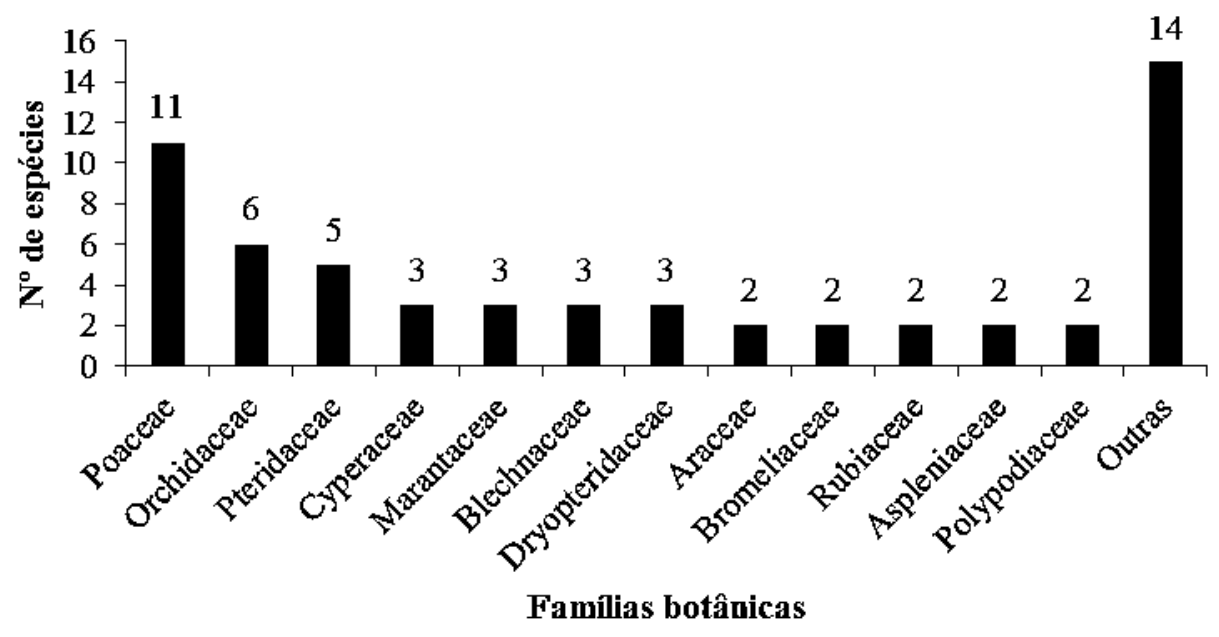

Figura 2. Distribuição das espécies herbáceas terrícolas amostradas por família na mata ciliar da sub-bacia do rio Urussanga, Santa Catarina, Brasil.

Quanto a maior riqueza de Poaceae encontrada, destaca-se que, embora os seus representantes predominem em formações campestres, sendo menos comuns em formações florestais, suas espécies apresentam grande amplitude ecológica, podendo habitar diversos ecossistemas (Welker e Longhi-Wagner, 2008). A riqueza de espécies de Poaceae encontradas no interior dos remanescentes de mata ciliar amostrados pode estar relacionada à composição do uso da terra no entorno, pois, ao longo dos trechos estudados, encontram-se áreas destinadas a pastagens e cultivos, assim como estradas, o que propicia a entrada de luz pela fragmentação e efeito de borda, facilitando o estabelecimento das espécies de gramíneas que se desenvolvem com maior luminosidade do ambiente. Santos-Junior (2014) amostrou cinco espécies de Poaceae em um remanescente de Floresta Atlântica secundária, enquanto que, na floresta primária, nenhuma espécie desta família foi encontrada. Orchidaceae também contribuiu com grande riqueza $(n=6)$, quando comparado a outros estudos nos quais esta família se destaca, visto que, geralmente, seus representantes são de espécies epifíticas (Palma et al., 2008).

Tabela 1. Espécies encontradas no levantamento florístico da vegetação herbácea terrícola ciliar do município de Urussanga, Santa Catarina, Brasil, e suas respectivas formas de vida, em que: CRI= número de registro no Herbário CRI.

\begin{tabular}{llc}
\hline \multicolumn{1}{c}{ Forma de vida/Nome científico } & Família & CRI \\
\hline Caméfito herbáceo & & 10157 \\
Celosia grandifolia Moq. & Amaranthaceae & 11481 \\
Dorstenia carautae C.C. Berg & Moraceae & \\
Geófita rizomatosa & & $* *$ \\
Asterostigma tweedianum Schott & Araceae & $* *$ \\
Ctenanthe sp. & Marantaceae & $* *$ \\
Goeppertia monophylla (Vell.) Borchs. e S.Suárez & Marantaceae & $* *$ \\
Hedychium coronarium J. Koenig* & Zingiberaceae & 10158 \\
Heliconia farinosa Raddi & Heliconiaceae & 11494 \\
Ichnanthus leiocarpus (Spreng.) Kunth & Poaceae & 11480 \\
Maranta arundinacea L. & Marantaceae & $* *$ \\
Oxalis sp. & Oxalidaceae & \\
\hline
\end{tabular}

Continua.... 
Continuação...

\begin{tabular}{l} 
Forma de vida/Nome científico \\
\hline Pleurostachys gaudichaudii Brongn. \\
Pleurostachys urvillei Brongn. \\
Polybotrya cylindrica Kaulf. \\
Serpocaulon latipes (Langsd. e Fisch.) A.R. Sm. \\
Tectaria pilosa (Fée) R.C. Moran
\end{tabular}

Thelypteris sp.

\section{Hemicriptófita cespitosa}

Carex seticulmis Boeckeler

Doryopteris concolor (Langsd. e Fisch.) Kuhn

Olyra latifolia L.

Paspalum corcovadense Raddi

Pharus lappulaceus Aubl.

Streptochaeta spicata Schrad. ex Nees

$\begin{array}{lc}\text { Família } & \text { CRI } \\ \text { Cyperaceae } & 10156 \\ \text { Cyperaceae } & * * \\ \text { Dryopteridaceae } & * * \\ \text { Polypodiaceae } & * * \\ \text { Tectariaceae } & * * \\ \text { Thelypteridaceae } & * * \\ & \\ \text { Cyperaceae } & * * \\ \text { Pteridaceae } & 11498 \\ \text { Poaceae } & 11478 \\ \text { Poaceae } & 11476 \\ \text { Poaceae } & 11490 \\ \text { Poaceae } & 11493 \\ & \\ \text { Orchidaceae } & 11492 \\ \text { Orchidaceae } & 11488\end{array}$

\section{Hemicriptófita escaposa}

Liparis nervosa (Thunb.) Lindl.

Malaxis excavata (Lindl.) Kuntze

Orchidaceae

\section{Hemicriptófita reptante}

Adiantum pentadactylon Langsd. e Fisch.

Asplenium sp.1

Asplenium sp.2

Blechnum acutum (Desv.) Mett.

Pteridaceae

Aspleniaceae

**

Aspleniaceae

Blechnaceae

Centella asiatica (L.) Urb.*

Apiaceae

Coccocypselum cordifolium Nees e Mart.

Rubiaceae

Coccocypselum geophiloides Wawra

Rubiaceae

Dichanthelium sabulorum (Lam.) Gould e C.A. Clark

Poaceae

Ichnanthus pallens (Sw.) Munro ex Benth.

Poaceae

Lastreopsis amplissima (C. Presl) Tindale

Dryopteridaceae

Panicum sp.1

Poaceae

Poaceae

Parodiophyllochloa ovulifera (Trin.) Zuloaga e Morrone

Poaceae

Pecluma chnoophora (Kunze) Salino e Costa Assis

Polypodiaceae

Psilochilus modestus Barb. Rodr.

Orchidaceae

Pteris brasiliensis Raddi

Pteridaceae

Rugoloa pilosa (Sw.) Zuloaga

Poaceae

Selaginella marginata (Humb. e Bonpl. ex Willd.) Spring

Selaginellaceae

Commelinaceae

Tradescantia umbraculifera Hand.-Mazz.

Anemiaceae

Anemia phyllitidis (L.) Sw.

Blechnaceae

Blechnum polypodioides Raddi

Blechnaceae

Bromelia antiacantha Bertol.

Bromeliaceae 
Continuação...

\begin{tabular}{llc}
\hline \multicolumn{1}{c}{ Forma de vida/Nome científico } & Família & CRI \\
\hline Chaptalia nutans (L.) Pol. & Asteraceae & $* *$ \\
Cyclopogon variegatus Barb. Rodr. & Orchidaceae & 11491 \\
Deparia petersenii (Kunze) M. Kato* & Athyriaceae & 11484 \\
Doryopteris pedata (L.) Fée & Pteridaceae & $* *$ \\
Nidularium innocentii Lem. & Bromeliaceae & $* *$ \\
Prescottia stachyodes (Sw.) Lindl. & Orchidaceae & $* *$ \\
Pteris decurrens C. Presl & Pteridaceae & $* *$ \\
Stigmatosema polyaden (Vell.) Garay & Orchidaceae & $* *$ \\
Hemiepífita & & \\
Mickelia scandens (Raddi) R.C. Moran et al. & Dryopteridaceae & 11482 \\
Philodendron appendiculatum Nadruz e Mayo & Araceae & $* *$ \\
Saprófita & & \\
Voyria aphylla (Jacq.) Pers. & Gentianaceae & 11500 \\
\hline
\end{tabular}

"Espécie exótica;

*** Coleta de material sem estruturas reprodutivas.

Quanto às famílias de samambaias e licófitas, as que contribuíram com maior riqueza específica foram Pteridaceae $(n=5)$, Blechnaceae e Dryopteridaceae $(n=3)$. As demais famílias, em número de dez, contribuíram com duas ou apenas uma espécie cada. Estas famílias de samambaias são conhecidas por serem bem representadas nos ecossistemas florestais brasileiros (Dittrich et al., 2005; Gonzatti et al., 2014; Custódio, 2015; Teixeira et al., 2015) e o destaque obtido para este grupo, neste estudo, pode estar relacionado à heterogeneidade dos ambientes amostrados, diferindo na distância das margens dos rios, proximidade de áreas rurais, urbanas e estradas, além do grau de conservação em cada parcela. As samambaias consistem em um grupo de plantas que apresentam grande plasticidade ecológica, decorrente dos tipos de hábitos das espécies, podendo se desenvolver em diversos tipos de ambientes (Gasper et al., 2012).

Quanto à classificação em formas de vida das espécies encontradas, o grupo das hemicriptófitas reptantes foi o mais representativo, com 19 espécies, seguido por geófitas rizomatosas (14), hemicriptófitas rosuladas (12), hemicriptófitas cespitosas (6) e as demais formas de vida (7). O grupo das hemicriptófitas, em geral, predominou neste estudo (67\%) e também em outros com herbáceas terrícolas (Citadini-Zanette, 1984; Cestaro et al., 1986; Müller e Waechter, 2001); dentre elas, predominaram as hemicriptófitas reptantes. Este resultado também foi constatado nos estudos de Cestaro et al. (1986) e Müller e Waechter (2001), que atribuem a maior ocorrência das hemicriptófitas reptantes à possível presença de gado na área de estudo, relacionando à capacidade de reprodução vegetativa, a qual permite maior resistência ao pisoteio e ao pastejo. Muitos dos locais amostrados pertencem a propriedades rurais particulares, onde há presença de gado, que caminha próximo e, até mesmo, no interior das áreas de mata ciliar, o que pode sugerir esta relação com as hemicriptófitas reptantes. Além disso, as gramíneas (Poaceae) foram as que mais contribuíram para esta forma biológica.

As geófitas rizomatosas, segunda classe mais representativa neste estudo (24\%), também podem suportar a pressão do pastoreio por ter suas gemas no interior do solo (Citadini-Zanette e Baptista, 1989; Pettit et al., 1995), o que evidencia a resistência e a predominância dessas espécies, que apresentam maior proteção de suas gemas, principalmente em ambientes mais extremos (Kornás, 1985). 
A distribuição das espécies herbáceas e subarbustivas em uma floresta está relacionada a uma interação complexa entre diversos fatores, como, por exemplo, luminosidade, disponibilidade de água, tipo de solo e altitude (Inácio e Jarenkow, 2008; Kozera et al., 2009). As formas de vida encontradas neste trabalho mostram como as espécies buscam aperfeiçoar e ocupar o nicho do estrato inferior disponível nas florestas, uma vez que plantas reptantes e rizomatosas podem explorar o meio em que se encontram, deslocando o sentido de seu crescimento em direção as áreas mais iluminadas, enquanto as formas de vida rosulada e cespitosa podem captar maior luminosidade por meio de suas folhas mais largas e espiraladas (Kozera et al., 2009).

Nos parâmetros fitossociológicos, G. monophylla apresentou maior valor de importância, seguida por B. brasiliense, $H$. farinosa e $N$. innocentii (Tabela 2). Essas quatro espécies juntas perfazem $43 \%$ do valor de importância dentre as 58 espécies amostradas. Para as duas primeiras espécies, o valor de importância resultou de suas altas frequências e coberturas e, para a terceira, foi resultado, principalmente, de sua alta cobertura pela grande dimensão de suas folhas.

Tabela 2. Parâmetros fitossociológicos estimados para as espécies herbáceas terrícolas, ordenados de forma decrescente pelo índice de valor de importância (IVI), amostradas na mata ciliar da Sub-bacia do Rio Urussanga, Santa Catarina, Brasil, em que: NP = número de parcelas com a presença da espécie, $\mathrm{FA}=$ frequência absoluta, $\mathrm{FR}=$ frequência relativa $(\%), \mathrm{CA}=$ cobertura absoluta, $\mathrm{CR}=$ cobertura relativa (\%) e IVI = índice de valor de importância (\%).

\begin{tabular}{lcccccc}
\hline \multicolumn{1}{c}{ Nome científico } & NP & FA & FR & CA & CR & IVI \\
\hline Goeppertia monophylla & 29 & 46 & 10,51 & 204 & 20,4 & 15,45 \\
Blechnum brasiliense & 30 & 48 & 10,87 & 164 & 16,4 & 13,64 \\
Heliconia farinosa & 21 & 33 & 7,61 & 89 & 8,9 & 8,23 \\
Nidularium innocentii & 17 & 27 & 6,16 & 61 & 6,1 & 6,12 \\
Coccocypselum cordifolium & 12 & 19 & 4,35 & 45 & 4,5 & 4,41 \\
Anemia phyllitidis & 11 & 17 & 3,99 & 42 & 4,2 & 4,08 \\
Dorstenia carautae & 10 & 16 & 3,62 & 36 & 3,6 & 3,60 \\
Malaxis excavata & 10 & 16 & 3,62 & 14 & 1,4 & 2,51 \\
Pleurostachys gaudichaudii & 7 & 11 & 2,54 & 21 & 2,1 & 2,31 \\
Olyra latifólia & 7 & 11 & 2,54 & 20 & 2,0 & 2,26 \\
Cyclopogon variegatus & 9 & 14 & 3,26 & 10 & 1,0 & 2,13 \\
Ctenanthe sp. & 4 & 6 & 1,45 & 25 & 2,5 & 1,97 \\
Adiantum pentadactylon & 4 & 6 & 1,45 & 21 & 2,1 & 1,77 \\
Ichnanthus pallens & 5 & 8 & 1,81 & 16 & 1,6 & 1,70 \\
Rugoloa pilosa & 5 & 8 & 1,81 & 15 & 1,5 & 1,65 \\
Bromelia antiacantha & 4 & 6 & 1,45 & 17 & 1,7 & 1,57 \\
Liparis nervosa & 6 & 10 & 2,17 & 9 & 0,9 & 1,53 \\
Tradescantia umbraculifera & 3 & 5 & 1,09 & 19 & 1,9 & 1,49 \\
Panicum sp.1 & 4 & 6 & 1,45 & 15 & 1,5 & 1,47 \\
Paspalum corcovadense & 4 & 6 & 1,45 & 13 & 1,3 & 1,37 \\
Maranta arundinacea & 4 & 6 & 1,45 & 12 & 1,2 & 1,32 \\
Pteris brasiliensis & 4 & 6 & 1,45 & 8 & 0,8 & 1,12 \\
Blechnum acutum & 4 & 6 & 1,45 & 7 & 0,7 & 1,07 \\
Carex seticulmis & 3 & 5 & 1,09 & 10 & 1,0 & 1,04 \\
\hline Con & & & & & &
\end{tabular}

Continua... 
Continuação...

\begin{tabular}{|c|c|c|c|c|c|c|}
\hline Nome científico & NP & FA & FR & $\mathrm{CA}$ & $\mathrm{CR}$ & IVI \\
\hline Pharus lappulaceus & 3 & 5 & 1,09 & 9 & 0,9 & 0,99 \\
\hline Dichanthelium sabulorum & 3 & 5 & 1,09 & 7 & 0,7 & 0,89 \\
\hline Pleurostachys urvillei & 3 & 5 & 1,09 & 6 & 0,6 & 0,84 \\
\hline Asplenium sp.1 & 3 & 5 & 1,09 & 5 & 0,5 & 0,79 \\
\hline Doryopteris concolor & 2 & 3 & 0,72 & 8 & 0,8 & 0,76 \\
\hline Stigmatosema polyaden & 3 & 5 & 1,09 & 4 & 0,4 & 0,74 \\
\hline Hedychium coronarium & 2 & 3 & 0,72 & 6 & 0,6 & 0,66 \\
\hline Chaptalia nutans & 2 & 3 & 0,72 & 3 & 0,3 & 0,51 \\
\hline Lastreopsis amplissima & 2 & 3 & 0,72 & 3 & 0,3 & 0,51 \\
\hline Polybotrya cylindrica & 2 & 3 & 0,72 & 3 & 0,3 & 0,51 \\
\hline Psilochilus modestus & 2 & 3 & 0,72 & 3 & 0,3 & 0,51 \\
\hline Thelypteris sp. & 2 & 3 & 0,72 & 3 & 0,3 & 0,51 \\
\hline Celosia grandifolia & 2 & 3 & 0,72 & 2 & 0,2 & 0,46 \\
\hline Deparia petersenii & 2 & 3 & 0,72 & 2 & 0,2 & 0,46 \\
\hline Ichnanthus leiocarpus & 2 & 3 & 0,72 & 2 & 0,2 & 0,46 \\
\hline Centella asiatica & 1 & 2 & 0,36 & 4 & 0,4 & 0,38 \\
\hline Blechnum polypodioides & 1 & 2 & 0,36 & 3 & 0,3 & 0,33 \\
\hline Asplenium sp.2 & 1 & 2 & 0,36 & 3 & 0,3 & 0,33 \\
\hline Serpocaulon latipes & 1 & 2 & 0,36 & 3 & 0,3 & 0,33 \\
\hline Voyria aphylla & 1 & 2 & 0,36 & 3 & 0,3 & 0,33 \\
\hline Asterostigma tweedianum & 1 & 2 & 0,36 & 2 & 0,2 & 0,28 \\
\hline Doryopteris pedata & 1 & 2 & 0,36 & 2 & 0,2 & 0,28 \\
\hline Selaginella marginata & 1 & 2 & 0,36 & 2 & 0,2 & 0,28 \\
\hline Streptochaeta spicata & 1 & 2 & 0,36 & 2 & 0,2 & 0,28 \\
\hline Tectaria pilosa & 1 & 2 & 0,36 & 2 & 0,2 & 0,28 \\
\hline Coccocypselum geophiloides & 1 & 2 & 0,36 & 1 & 0,1 & 0,23 \\
\hline Mickelia scandens & 1 & 2 & 0,36 & 1 & 0,1 & 0,23 \\
\hline Oxalis sp. & 1 & 2 & 0,36 & 1 & 0,1 & 0,23 \\
\hline Panicum sp. 2 & 1 & 2 & 0,36 & 1 & 0,1 & 0,23 \\
\hline Parodiophyllochloa ovulifera & 1 & 2 & 0,36 & 1 & 0,1 & 0,23 \\
\hline Philodendron appendiculatum & 1 & 2 & 0,36 & 1 & 0,1 & 0,23 \\
\hline Pecluma chnoophora & 1 & 2 & 0,36 & 1 & 0,1 & 0,23 \\
\hline Prescottia stachyodes & 1 & 2 & 0,36 & 1 & 0,1 & 0,23 \\
\hline Pteris decurrens & 1 & 2 & 0,36 & 1 & 0,1 & 0,23 \\
\hline Total & 63 & 435 & 100 & 994 & 100 & 100 \\
\hline
\end{tabular}

Mallmann et al. (2016), ao estudarem samambaias herbáceas em trechos de mata ciliar, concluíram que a estrutura desse componente tende a ser simplificada quanto maior a alteração do ambiente natural. Como resultado dessa simplificação, encontram-se poucas espécies, concentrando a maior porcentagem dos valores de importância.

Goeppertia monophylla, Blechnum brasiliense e Heliconia farinosa, que se destacaram neste estudo, também foram citadas no estudo de Santos-Junior (2014), que avaliou a relação das comunidades herbáceas terrícolas com as características ambientais de Floresta Atlântica 
primária e secundária do sul do Brasil, em que G. monophylla e H. farinosa foram abundantes tanto na floresta primária como na secundária, enquanto que $B$. brasiliense foi abundante e exclusiva da floresta secundária.

Goeppertia monophylla é uma espécie que frequentemente se desenvolve em locais úmidos, sombreados e próximos a cursos d'água (Vieira et al., 2012). No estudo de Jurinitz e Baptista (2007), que compararam as monocotiledôneas terrícolas entre duas áreas distintas de Floresta Atlântica, uma bem drenada e outra paludosa, G. monophylla apresentou maior contribuição entre as ervas terrícolas, com ocorrência em ambas as áreas amostradas.

A samambaia $B$. brasiliense foi amostrada em seis trechos dos sete rios estudados, contribuindo com a maior frequência entre as parcelas. Esta espécie ocorre geralmente próxima a córregos, tanto em ambientes com maior luminosidade como nos mais sombreados (Sehnem, 1968). No estudo de Kozera et al. (2009), foi observada a presença de B. brasiliense apenas em condições de maior luminosidade, provocada por clareiras formadas pela queda de algumas árvores de grande porte, não sendo registrada em outros ambientes no interior da floresta.

As samambaias mais representativas neste estudo, B. brasiliense e A. phyllitidis, são espécies tolerantes a locais com baixa qualidade ambiental (Mallmann et al., 2016) e ocorrem predominantemente em florestas alteradas (Custódio, 2015).

Quanto à produção científica, foram encontrados 50 trabalhos indexados nas bases de dados eletrônicas, no período de 1990 a 2015, com espécies herbáceas terrícolas (Figura 3). O ano com maior quantidade de indexações foi 2011, com seis trabalhos, seguido dos anos de 2002 e 2010, com quatro trabalhos cada. No período analisado, os anos de 1992, 1997, 1998 e 2006 não foram indexados artigos sobre o tema.

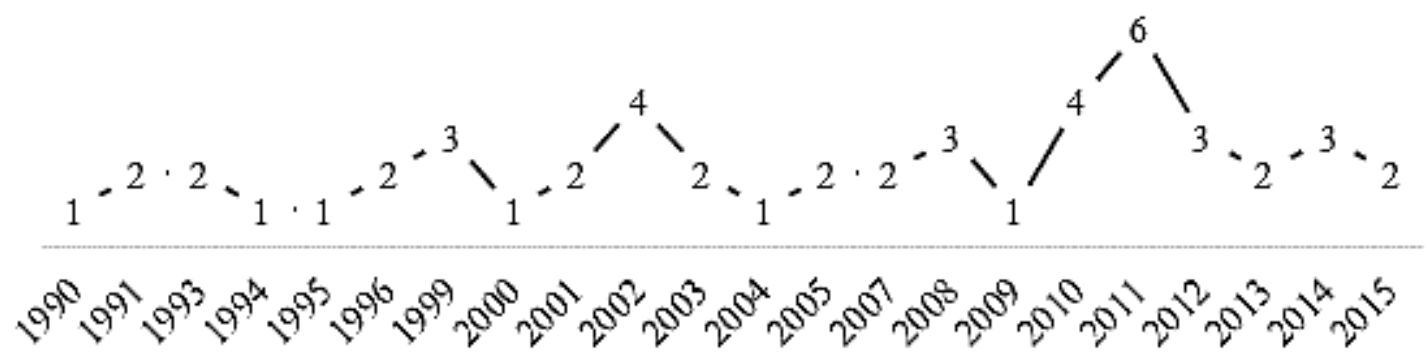

Figura 3. Distribuição dos artigos indexados.ano ${ }^{-1}(1990$ a 2015) sobre as espécies vegetais herbáceas terrícolas, nas bases de dados "SciVerse Scopus" e "Web of Science".

Sobre a produção científica, poucos trabalhos foram indexados nas bases de dados analisadas, revelando pouco interesse em relação ao estudo com as espécies vegetais herbáceas terrícolas florestais, como constatado por Jones et al. (2014). A maior parte das publicações está concentrada entre os anos de 2002 e 2011, reforçando um atual aumento no interesse pela temática, mesmo que de forma sutil. Este período coincide com poucos trabalhos direcionados à diversidade de espécies; portanto, não tão específicas, sendo mais frequentes as citações secundárias. Contudo, é relevante a distinção nos assuntos abordados em cada artigo.

Grande parte dos trabalhos publicados sobre as herbáceas terrícolas florestais está relacionada ao grupo dos primatas, tanto que os periódicos que receberam o maior número de trabalhos foram o "African Journal of Ecology, American Journal of Primatology, International Journal of Primatology" e "Primates", todos específicos da área. Em geral, estes trabalhos abordaram a importância desse grupo de plantas, em especial, pela disponibilidade de alimentos e alternativa de habitats para os primatas (Kaplin e Moermond, 2000; Georgiev et al., 2011). 
Estudos com diversidade de espécies herbáceas terrícolas, ainda que escassos, foram realizados. Recentemente, Jones et al. (2014) publicaram no "Journal of Vegetation Science" um estudo desenvolvido na Indonésia, que teve como objetivo, entre outros, conhecer a diversidade e estrutura da comunidade herbácea terrícola em floresta tropical submontana, descrevendo um total de 184 espécies. No Brasil, apenas um trabalho foi indexado abordando as herbáceas terrícolas, publicado na Revista Brasileira de Botânica, por Inácio e Jarenkow (2008), o qual foi realizado em floresta estacional no sul do país, resultando no levantamento de 29 espécies.

\section{CONCLUSÕES}

A proteção de recursos hídricos e a formação de corredores ecológicos são alguns dos serviços ambientais prestados pelas matas ciliares na Sub-bacia do Rio Urussanga, no sul de Santa Catarina, Brasil. A vegetação herbácea terrícola, embora seja pouco contemplada nos estudos em relação às lenhosas, pode fornecer informações relevantes sobre o ambiente em que se encontra. Na área de estudo, foi encontrada elevada riqueza dessas espécies contribuindo para a diversidade de sua flora. A predominância de determinados grupos pode sugerir características locais do ambiente, como no caso das espécies que se desenvolvem com a incidência de luz no solo e outras que são típicas de florestas alteradas.

Apesar do baixo número de indexações das herbáceas terrícolas, a temática é relevante, principalmente por contribuir para a estrutura comunitária e ser indicadora de ambientes no interior da floresta. No entanto, o número de indexações tende a crescer, evidenciado pelo conteúdo diverso tratado em cada trabalho, apoiado pelo avanço da tecnologia de acesso às bases de dados eletrônicas e pela crescente adesão de periódicos a estes portais de busca.

Com isso, este estudo contribuiu para o conhecimento das herbáceas terrícolas do sul do Brasil, demonstrando a importância dos fragmentos ciliares para a conservação da biodiversidade local.

\section{AGRADECIMENTOS}

Agradecemos o apoio financeiro da Coordenação de Aperfeiçoamento de Pessoal de Nível Superior (PROSUP/CAPES-UNESC), pelo financiamento de bolsas de estudo dos três primeiros autores, e à Universidade do Extremo Sul Catarinense (UNESC), pela infraestrutura oferecida para o desenvolvimento deste estudo.

\section{REFERÊNCIAS}

CAUSTON, N. D. An introduction to vegetation analysis: principles and interpretation. London: Unwin Hyman, 1988. 342 p.

CESTARO, L. A.; WAECHTER, J. L.; BAPTISTA, L. R. M. Fitossociologia do estrato herbáceo da mata de araucária da Estação Ecológica de Aracuri, Esmeralda, RS. Hoehnea, v. 13, p. 59-72, 1986.

CITADINI-ZANETTE, V.; BAPTISTA, L. R. D. M. Vegetação herbácea terrícola de uma comunidade florestal em Limoeiro, município de Torres, Rio Grande do Sul, Brasil. Boletim do Instituto de Biociências, v. 45, p. 1-87, 1989.

CITADINI-ZANETTE, V. Composição florística e fitossociologia de vegetação herbácea terrícola de uma Mata de Torres, Rio Grande do Sul, Brasil. Iheringia, v. 32, p. 23-62, 1984. 
CITADINI-ZANETTE, V.; PEREIRA, J. L.; JARENKOW, J. A.; KLEIN, A. S.; SANTOS, R. Estrutura da sinúsia herbácea em Floresta Ombrófila Mista no Parque Nacional de Aparados da Serra, sul do Brasil. Revista Brasileira de Biociências, v. 9, n. 1, p. 5663, 2011.

CITADINI-ZANETTE, V.; SANTOS, R.; EMERICH, K. H.; PASETTO, M. R.; CEMIN, J. G.; FERNANDES, M. B. Composição florística de um fragmento florestal ciliar no sul de Santa Catarina. Revista de Tecnologia e Ambiente, v. 20, p. 55-70, 2014. http://dx.doi.org/10.18616/ta.v20i0.1560

CUSTÓDIO, S. Z. Samambaias e Licófitas do Parque Estadual da Serra Furada, Orleans, SC. 2015. 80 f. Dissertação (Mestrado em Ciências Ambientais) Universidade do Extremo Sul Catarinense, Criciúma, 2015.

DITTRICH, V. A. O.; WAECHTER, J. L.; SALINO, A. Species richness of pteridophytes in a montane Atlantic rain forest plot of Southern Brazil. Acta Botanica Brasilica, v. 19, n. 3, p. 519-525, 2005. http://dx.doi.org/10.1590/S0102-33062005000300013

DORNELES, L. P. P.; NEGRELLE, R. R. B. Composição florística e estrutura do compartimento herbáceo de um estágio sucessional avançado da Floresta Atlântica, no sul do Brasil. Biotemas, v. 12, n. 2, p. 7-30, 1999.

DURIGAN, G.; SILVEIRA, E. R. Recomposição de mata ciliar em domínio de cerrado, Assis, SP. Scientia Forestalis, n. 56, p.15-28, 1999.

EMPRESA BRASILEIRA DE PESQUISA AGROPECUÁRIA - EMBRAPA. Centro Nacional de Pesquisa de Solos. Sistema brasileiro de classificação de solos. Brasília: Sistema de Produção e Informação, 1992. 77 p.

EMPRESA DE PESQUISA AGROPECUÁRIA E EXTENSÃO RURAL DE SANTA CATARINA - EPAGRI. Dados e informações biofísicas da Unidade de Planejamento Regional Litoral Sul Catarinense: UPR 8. Florianópolis, 2001. 81 p.

FERNÁNDEZ, D.; BARQUÍN, J.; ÁLVAREZ-CABRIA, M.; PEÑAS, J. Land-use coverage as an indicator of riparian quality. Ecological Indicators, v. 41, p. 165-174, 2014. http://dx.doi.org/10.1016/j.ecolind.2014.02.008

FERREIRA, D. A. C.; DIAS, H. C. T. Situação atual da mata ciliar do ribeirão São Bartolomeu em Viçosa, MG. Revista Árvore, v. 28, n. 4, p. 617-623, 2004. http://dx.doi.org/10.1590/S0100-67622004000400016

FREITAS, S. R.; HAWBAKER, T. J.; METZGER, J. P. Effects of roads, topography, and land use on forest cover dynamics in the Brazilian Atlantic Forest. Forest Ecology and Management, v. 259, p. 410-417, 2010. http://dx.doi.org/10.1016/j.foreco.2009.10.036

FUHRO, D.; VARGAS, D. D.; LAROCCA, J. Levantamento florístico das espécies herbáceas, arbustivas e lianas da Floresta de Encosta da Ponta do Cego, Reserva Biológica do Lami (RBL), Porto Alegre, Rio Grande do Sul, Brasil. Pesquisas, Botânica, v. 1, p. 239-256, 2005.

GASPER, A. L.; SALINO, A.; VIBRANS, A. C.; SEVEGNANI, L.; VERDI, M.; KORTE, A. et al. Pteridófitas de Santa Catarina: um olhar sobre os dados do inventário florístico florestal de Santa Catarina, Brasil. Acta Botanica Brasilica, v. 26, n. 2, p. 421-434, 2012. http://dx.doi.org/10.1590/S0102-33062012000200018 
GEORGIEV, A.; THOMPSON M. E.; LOKASOLA, A.; WRANGHAM, R. W. Seedpredation by bonobos (Pan paniscus) at Kokolopori, Democratic Republic of Congo. Primates, v. 52, p. 309-314, 2011. http://dx.doi.org/10.1007/s10329-011-0256-4

GILLIAM, F. S. The ecological significance of the herbaceous layer in temperate forest ecosystems. BioScience, v. 57, n. 10, p. 845-858, 2007.

http://dx.doi.org/10.1641/B571007

GONZATTI, F.; VALDUGA, E.; WASUM, R. A.; SCUR, L. Florística e aspectos ecológicos de samambaias elicófitas em remanescentes de matas estacionais deciduais da serra gaúcha, Rio Grande do Sul, Brasil. Revista Brasileira de Biociências, v. 12, n. 2, p. 90-97, 2014.

HORA, R. C.; SOARES, J. J. Estrutura fitossociológica da comunidade de lianas em uma Floresta Estacional Semidecidual na Fazenda Canchim, São Carlos, SP. Revista Brasileira de Botânica, v. 25, n. 3, p. 323-329, 2002.

INSTITUTO BRASILEIRO DE GEOGRAFIA E ESTATÍSTICA - IBGE. manual técnico da vegetação brasileira. Rio de Janeiro, 2012. 274 p.

INÁCIO, C. D.; JARENKOW, J. A. Relações entre a estrutura da sinúsia herbácea terrícola e a cobertura do dossel em floresta estacional no Sul do Brasil. Brazilian Journal of Botany, v. 31, n. 1, p. 41-51, 2008. http://dx.doi.org/10.1590/S010084042008000100005

JARDIM BOTÂNICO DO RIO DE JANEIRO. Flora do Brasil 2020 em construção. 2016. Disponível em: http://floradobrasil.jbrj.gov.br/. Acesso em: 10 jan. 2016.

JONES, M. M.; CICUZZA, D.; VAN STRAATEN, O.; VELDKAMP, E.; KESSLER, M. Determinants of fern and angiosperm herb community structure in lower montane rainforest in Indonesia. Journal of Vegetation Science, v. 25, n. 5, p. 1216-1224, 2014.

JURINITZ, C. F.; BAPTISTA, L. R. M. Monocotiledôneas terrícolas em um fragmento de Floresta Ombrófila Densa no litoral norte do Rio Grande do Sul. Revista Brasileira de Biociências, v. 5, n. 1, p. 9-17, 2007.

KAPLIN, B. A.; MOERMOND, T. C. Foraging ecology of the mountain monkey (Cercopithecus l'hoesti): implications for its evolutionary history and use of disturbed forest. American Journal of Primatology, v. 50, n. 4, p. 227-246, 2000. http://dx.doi.org/10.1002/(SICI)1098-2345(200004)50:4<227::AID-AJP1>3.0.CO;2-S

KLEIN, R. M. Mapa fitogeográfico de Santa Catarina. In: REITZ, R. (Ed.). Flora ilustrada catarinense. Itajaí: Herbário Barbosa Rodrigues, 1978. 24 p.

KLEIN, A. S.; CITADINI-ZANETTE, V.; SANTOS, R. Florística e estrutura comunitária de restinga herbácea no município de Araranguá, Santa Catarina. Biotemas, v. 20, n. 3, p. 15-26, 2007.

KORNÁS, J. Adaptative strategies of African pteridophytes to extreme enviroments. Proceedings of Royal Society of. Edinburgh. Section B. Biological Sciences, v. 86, p. 391-396, 1985. http://dx.doi.org/10.1017/S026972700000837X

KOZERA, C.; RODRIGUES, R. R.; DITTRICH, V. D. O. Composição florística do subbosque de uma Floresta Ombrófila Densa Montana, Morretes, PR, Brasil. Floresta, v. 39, n. 2, p. 323-334, 2009. 
MALLMANN, I. T.; SILVA, V. L.; SCHMITT, J. L. Estrutura comunitária de samambaias em mata ciliar: avaliação em gradiente de antropização. Revista Ambiente \& Água, v. 11, n. 1, 2016. http://dx.doi.org/10.4136/ambi-agua.1717

MENEZES, C. T. B.; WATERKEMPER, K. Evolução dos processos de degradação ambiental resultante da mineração de carvão em Santa Catarina de 1930-1973. In: MILIOLli, G.; SANTOS, R.; CITADINI-ZANETTE, V. (Coords.). Mineração de carvão, meio ambiente e desenvolvimento sustentável no sul de Santa Catarina: uma abordagem interdisciplinar. Curitiba: Juruá, 2009. p. 205-213.

MUELLER-DOMBOIS, D.; ELLENBERG, H. Aims and methods of vegetation ecology. New Jersey: The blackburn press, 2002. 547 p.

MULLER, S. C.; WAECHTER, J. L. Estrutura sinusial dos componentes herbáceo e arbustivo de uma floresta costeira subtropical. Revista Brasileira de Botânica, v. 24, n. 4, p. 395-406, 2001.

MYERS, N.; MITTERMEIER, R. A.; MITTERMEIER, C. G.; FONSECA da, G. A.; KENT, J. Biodiversity hotspots for conservation priorities. Nature, v. 403, p. 853-858, 2000. http://dx.doi.org/10.1038/35002501

NEGRELLE, R. R. B. Composição florística e estrutura vertical de um trecho de Floresta Ombrófila Densa de Planície Quaternária. Hoehnea, v. 3, p. 261-289, 2006.

PALMA, C. B.; INÁCIO, C. D.; JARENKOW, J. A. Florística e estrutura da sinúsia herbácea terrícola de uma floresta estacional de encosta no Parque Estadual de Itapuã, Viamão, Rio Grande do Sul. Revista Brasileira de Biociências, v. 6, n. 3, p. 151-158, 2008.

PETTIT, N. E.; FROEND, R. H.; LADD, P. G. Grazing in remnant woodland vegetation: changes in species composition and life form groups. Journal of Vegetation Science, v. 6, n. 1, p. 121-130, 1995. http://dx.doi.org/10.2307/3236263

POLISEL, R. T. Análise fitossociológica do subosque de florestas com araucária e sua relação fitogeográfica com outras formações florestais da Floresta Atlântica s.l. 2011. 177 f. Dissertação (Mestrado em Biologia Vegetal) - Universidade Estadual de Campinas, Campinas, 2011.

POLISEL, R. T.; ASSIS, M. C.; YAMAMOTO, K.; IVANAUSKAS, N. M. Componente residente do sub-bosque em florestas com araucária no estado de São Paulo. In: CARDOSO, E. J. B. N.; VASCONCELOS, R. L. F. Floresta com araucária: composição florística e biota do solo. Piracicaba: FEALQ, 2015. p. 63-90.

SANTOS-JUNIOR, R. D. Comunidades herbáceas terrícolas em floresta atlântica primária e secundária no sul do Brasil. 2014. 36 f. Dissertação (Mestrado em Botânica) - Universidade Federal do Rio Grande do Sul, Porto Alegre, 2014.

SCHORN, L. A.; GASPER, A. L. D.; MEYER, L.; VIBRANS, A. C. Síntese da estrutura dos remanescentes florestais em Santa Catarina. In: VIBRANS, A. C.; SEVEGNANI, L.; GASPER, A. L. D.; LINGNER, D. V. D. (Ed.). Inventário florístico florestal de Santa Catarina: diversidade e conservação dos remanescentes florestais. Blumenau: Edifurb, 2012. p.125-140.

SEHNEM, A. Blecnáceas. Itajaí: Herbário Barbosa Rodrigues, 1968. 90 p. 
SEVEGNANI, L.; GASPER, A. L. D.; BONNET, A.; SOBRAL, M. G.; VIBRANS, A. C.; VERDI, M. et al. Flora vascular da floresta ombrófila densa em Santa Catarina. In: VIBRANS, A. C.; SEVEGNANI, L.; GASPER, A. L. D.; LINGNER, D. V. D. (Eds.). Inventário florístico florestal de Santa Catarina: floresta ombrófila densa. Blumenau: Edifurb, 2013. p.127-139.

TEIXEIRA, G.; MACIEL, S.; PIETROBOM, M. R. Potencial utilitário de licófitas e samambaias: aplicabilidade ao contexto amazônico. Biota Amazônia, v. 5, n. 1, p. 6873, 2015. http://dx.doi.org/10.18561/2179-5746/biotaamazonia.v5n1p68-73

VIEIRA, S.; FORZZA, R. C.; WANDERLEY, M. G. L. Maranthaceae. In: WANDERLEY, M. G. L.; SHEPHERD, G. J.; MELHEM, T. S.; MARTINS, S. E.; GIULIETTI, A. M. (Eds.). Flora fanerogâmica do estado de São Paulo. São Paulo: Fapesp, 2012. p. 205231.

VIBRANS, A. C.; MCROBERTS, R. E.; LINGNER, D. V. D.; NICOLETTI, A. L.; MOSER, P. Extensão original e remanescentes da Floresta Ombrófila Densa em Santa Catarina. In: VIBRANS, A. C.; SEVEGNANI, L.; GASPER, A. L. D.; LINGNER, D. V. D. (Eds.). Inventário florístico florestal de Santa Catarina: floresta ombrófila densa. Blumenau: Edifurb, 2013. p. 25-33.

WELKER, C. A. D.; LONGHI-WAGNER, H. M. A família Poaceae no Morro Santana, Rio Grande do Sul, Brasil. Revista Brasileira de Biociências, v. 5, n. 4, p. 53-92, 2008. 